Portland State University

PDXScholar

1990

\title{
Students' orientations toward dreams and the development of scales for their measurement
}

John Philip Governale

Portland State University

Follow this and additional works at: https://pdxscholar.library.pdx.edu/open_access_etds

Part of the Psychology Commons

Let us know how access to this document benefits you.

\section{Recommended Citation}

Governale, John Philip, "Students' orientations toward dreams and the development of scales for their measurement" (1990). Dissertations and Theses. Paper 4097.

https://doi.org/10.15760/etd.5981

This Thesis is brought to you for free and open access. It has been accepted for inclusion in Dissertations and Theses by an authorized administrator of PDXScholar. Please contact us if we can make this document more accessible: pdxscholar@pdx.edu. 
AI ABSTRACT OF THE THESIS OF John Phillp Governale for the degree of Master of Sctence in Psychology presented July 5, 1990.

Ittle: Students' Orientations Toward Dreams and the Development of Scales for their Measurement.

APPROVED BY MEMBERS OF THE THESIS COMMITTEE:
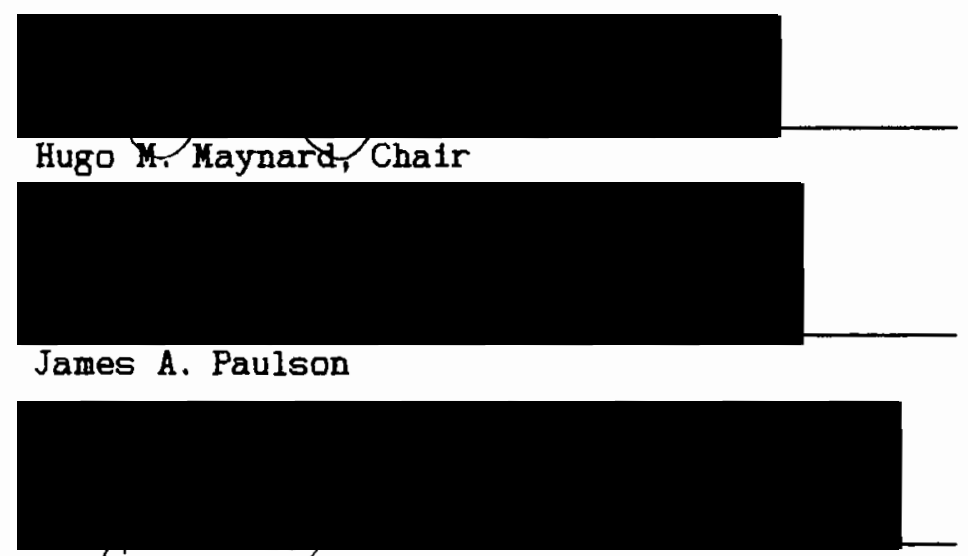

C. Kerth O'Brien

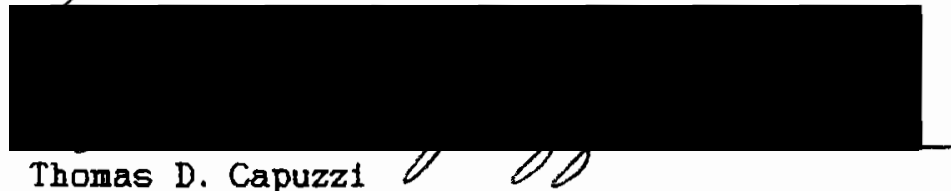

The present study explores the knowledge, attitudes, and opinions about dreams held by $394 \mathrm{high}$ school, community college, and unfversity students, and examines the interrelations among these students' responses to questions concerning such knowledge, attitudes, and opintons. A modifled and extended form of George Domino's Questionnatre About Dreams (QAD) was used for obtaining a descriptive account of students' orientations toward dreams. Scales were developed for summarizing respondents' or lentations 
toward dreams, and the reliabllity and validity of these scales was investigated. The rellability of scales for assessing respondents' attitudes, psychodynamic orientation, and to a lesser degree paranormal orientation was demonstrated. A reliable measure of factual knowledge about dreams was not demonstrated.

Overall, respondents possess a positive attitude or valence toward dreams, and are generally inclined toward a psychodynamic understanding of their nature, though some spectfically psychoanalytic views are eschewed. Most respondents were not inclined toward a paranormal or supernatural view of dreams. Lucid dreaming turned out to be a common occurrence. Respondents' factual knowledge appears to be rather unstructured.

Positive attitudes toward dreams were strongly related with psychodynamic orientation, and moderately related with factual knowledge and lucidity. Positive attitudes were negatively related to specifically psychoanalytic notions of dreaming.

Few age differences were found, and those found were weak. Significant sex differences were found, with women holding substantially stronger positive attitudes toward dreams than did men. Women were also moderately more inclined toward a psychodynamic understanding of dreams than were men, though they were substantially more averse than were men to a specifically psychoanalytic conception of dreams. Substantial differences were also found between schools in attitude, psychodynamic orientation, and paranormal orlentation, though the causes of these differences cannot presently be explained with any certainty. This study provides groundwork for future research wth a larger general population. 
STUDENTS' ORIENTATIONS TOVARD DREAMS AND THE DEVELOPMENT OF SCALES FOR THEIR MEASUREMENT

by

JOHN GOVERNALE

A thesis submitted in partial fulfillment of the requirements for the degree of

\author{
MASTER OF SCIENCE \\ in \\ PSYCHOLOGY
}

Portland State Unfversity

1990 
TO THE OFFICE OF GRADUATE STUDIES:

The members of the committee approve the thesis of John Philip Governale presented July 5, 1990.

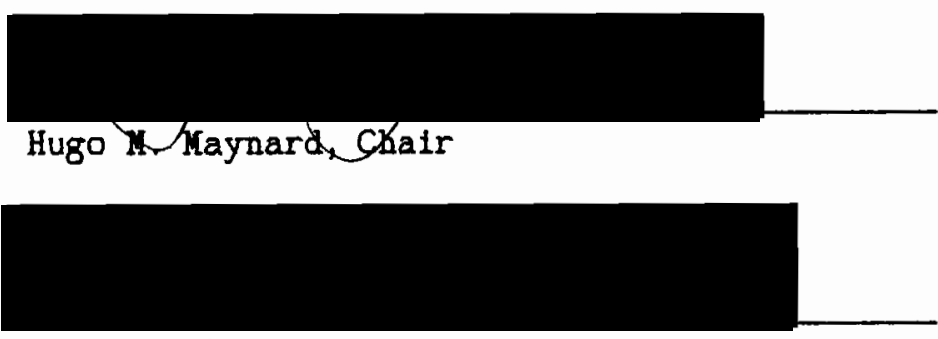

James A. Paulson

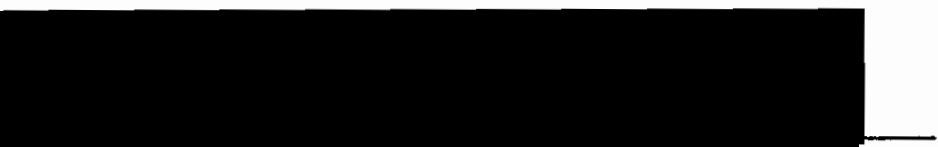

C. Kefth O'Brięh

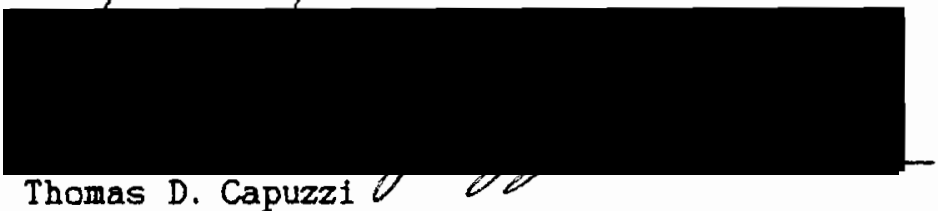

APPROVED:

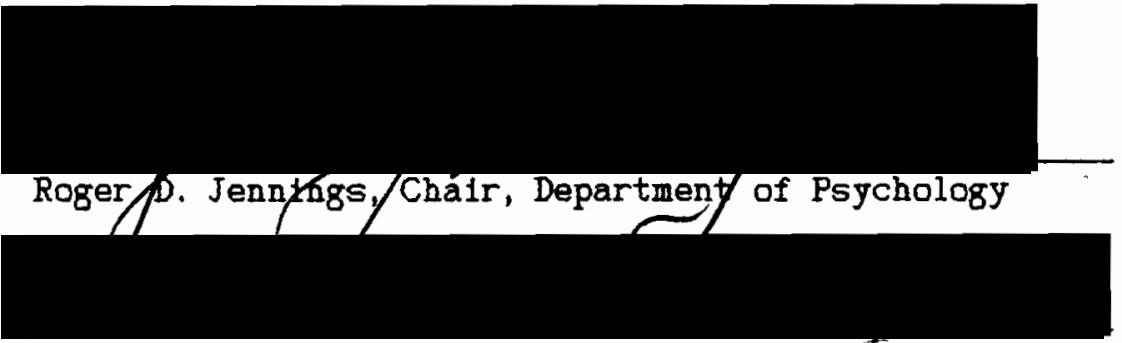

C. Willam Savery, Interim Vice Provost for Graduate Studies and Research 


\section{ACKNOWLEDGEYEHTS}

I would like to express my sincere gratitude for the guidance and encouragement provided by Hugo Maynard, James Paulson, and Kerth O'Brien, the members of my thesis committee. Their thoughtful comments and suggestions have added greatly to the quality of the finished product, and their enthuslasm has inspired my efforts along the way. 
TABLE OF CONTENTS

PAGE

ACKNOWLEDGEMENTS . . . . . . . . . . . . . . . . . . . . . . . III

LIST OF TABLES . . . . . . . . . . . . . . . . . . . . vi

IMTRODUCTION . . . . . . . . . . . . . . . . . . 1

Studies in Attitudes Toward Dreams . . . . . . . . . . . 5

METHODS . . . . . . . . . . . . . . . . . . 11

Subjects . . . . . . . . . . . . . . . . . 12

Instrument . . . . . . . . . . . . . . . 13

Scales . . . . . . . . . . . . . . . .15

RESULTS AND DISCUSSION . . . . . . . . . . . . . . . . . . 17

Comparison of High School Sample Responses . . . . . . . . . .17

Scale Development. . . . . . . . . . . . . . . . 20

Summary of Students' Orfentations Toward Dreams . . . . . . . .29

Age, Sex, and School Differences............ 35

Relationships Among Scales. . . . . . . . . . . . . . .39

Content Validity . . . . . . . . . . . . . . . . 42

CONCLUSION . . . . . . . . . . . . . . . . . . . . . 45

Future Research . . . . . . . . . . . . . . . . . . . .46

RBFEREICES . . . . . . . . . . . . . . . . . . . . . . 48 APPENDICES

A ORIGIMAL QUESTIOHHAIRE ABOUT DREAYS (QAD) ITEMS . . . .51 
PAGE

APPENDICES

B ATTITUDES TOWARD DREAKS SCALE (ATDS) ITEMS . . . . . . . 54

C EXTENDED QUESTIONNAIRE ABOUT DREAKS . . . . . . . . . . . 56

D PROVISIONAL QAD SCALES . . . . . . . . . . . . . . . . 60

E FIIIAL QAD SCALES . . . . . . . . . . . . . . . . . . 64 


\section{LIST OF TABLES}

TABLE

PAGE

I High School Students' Responses to Item 12: "God Can

Speak to Us Through Dreams.". . . . . . . . . . . 18

II High School Students" Responses to Item 16: "Understanding

One's Dreams Can Make Your Life Better.". . . . . . . 18

III High School Students' Responses to Item 25: "Dreams Are

Full of Symbols." . . . . . . . . . . . . . . . 19

IV Attitude Scale Summary . . . . . . . . . . . . . . 30

V Psychodynamic Or Ientation Scale Summary . . . . . . . . . 31

VI Freudian Orientation Scale Summary . . . . . . . . . . . . 32

VII Paranormal Orientation Scale Summary . . . . . . . . . 33

VII Lucidity Scale Sumary . . . . . . . . . . . . . . . 33

IX Factual Knowledge Scale Summary . . . . . . . . . . . . . 34

X Sex Differences in Scale Scores . . . . . . . . . . . . 37

XI School Differences in Scale Scores . . . . . . . . . . 38

XII Interscale Correlation Katrix . . . . . . . . . . . . 40 


\section{INTRODUCTION}

The historical record shows that human beings have long been fascinated by dreams. Numerous references to dreams can be found in anclent writings from many cultures, most of which attest that dreams were generally taken seriously. For example, the Bribad-aranyaka Upantshad (circa 800 B.C.E.) discusses the nature of dreams under the rubric, "The Supreme Teaching." The Bible, too, contains many reports of dreams and their interpretations, generally regarding them as augurles (e.g., Genesis 37, 5-10; Daniel 2, 28-46). In ancient Greece the interest in dreams was so great that Artemidorus of Daldis wrote a whole volume, Oneirocritica, on their interpretation in about $150 \mathrm{C.E}$. While we cannot be sure that, as a whole, the peoples of ancient India, Israel, and Greece regarded dreams as important, the evidence points in that direction.

With the rapid rise of sclence and positivism during the nineteenth century, many intellectuals began to regard dreams with disdain. The happenings in dreams did not conform to our burgeoning rational understanding of the world, and so they were thought of as confused products of the diminished functioning of the sleeping mind. Especially influential in this regard was the work of the French physictan Alfred Kaury, who collected and studled reports of over 3000 dreams, some of which were obtalned under experimental conditions. Maury argued that dreams are a bizarre amalgam of memory and imperfectly processed external stimuli that impinge on the sleeping mind (Maury, 1861/1878). 
Sigmund Freud reversed this deprecatory trend with his monumental work, The Interpretation of Dreams (1900/1953). Freud accounted for those aspects of dreams that differ from our waking understanding and experience of the world by devising a new model of the mind that was largely consistent both with the prevalling scientific knowledge and assumptions of his time, and with his personal and clinical experience with dreams.

Although Freud's ideas regarding dreams and the mind were opposed by many of his contemporarles, it is clear that his work defined many of the issues with which subsequent dream theorists have had to contend.

Freud distinguished the dream as recalled (the manifest dream) from the psychic motives (wishes) that instigated and found expression in the dream. In Freud's view the manifest dream is a disguised expression of latent dream-thoughts which are too personally threatening to be expressed directly. It follows from this position that people are, for the most part, incapable of properly understanding their own dreams without the aid of a specially trained, unbiased interpreter (1.e., a psychoanalyst), since the same forces that motivate dream censorship operate just as forcefully to limit our waking attempts at discovery.

The first serious challenge to Freud's disguise theory of dreams came from his early disciple, C. G. Jung. "The dream," wrote Jung, "is a natural occurrence, and there is no earthly reason why we should assume that it is a crafty device to lead us astray" (Jung, 1938/1969, p. 27). He argued that the dream is a message expressed in the natural language of the unconscious that is designed to compensate for imbalances in the dreamer's conscious attitude (Jung, 1916/1969). Like Freud, Jung developed an elaborate theory of the psyche based largely on his study of his own dreams and those of 
his clients. Many other theorists subsequently followed Jung's lead in rejecting Freud's disguise theory. Jung has also been influential due to the tremendous popular appeal of his work, especially in his encouraging attitude that ordinary people can promote their own psychological development through attending to their dreams (Jung, 1964).

The next major development in dream research was Calvin S. Hall's application of content analysis (as distinct from interpretation) to the study of dreams (Hall \& Van de Castle, 1966). Beginning in the 1940s, Hall began working on a standardized format for collecting dream reports (Faraday, 1972). Using his new format, Hall collected and analyzed thousands of dream reports. What is especially important about Hall's work is that it represents the first attempt to study the dream reports of a large sample of "normal" people. In all previous work most of the subjects whose dream reports were studied were people who had sought out some form of psychotherapy--hardly a representative sample of the population. The picture of dream life that emerged from Hall's efforts was considerably more mundane than that based on dream reports collected from samples of clinical populations. Hall's first major report of his findings, The Meaning of Dreams, was published in 1953.

Another major shift in the study of dreams began that same year, following Eugene Aserinsky and Nathaniel Kleitman's fortuitous discovery of rapid eye movements (REMs) occuring during sleep, and the corresponding discovery that upon being awakened from periods of REM sleep subjects usually reported vivid dreams (Aserinsky \& Kleitman, 1953). For the first time in history it was possible to know when subjects were dreaming, how often they dreamt, and how long their dreams lasted. The discovery that 
dreaming was associated with objectively observable signs spurred other investigations. REM sleep is now firmly established as a distinct phystological state (Hobson, 1988).

A whole host of questions arose from these discoverles, and a period of intensive scientific investigation into dreaming began that continues to this day. RsycIMEO references over a thousand articles dealing with dreams published in the last ten years (1979-1989). This intensive scrutiny of dreams has resulted in the posing and answering of a great many empirical questions: everyone dreams every night, we dream in color, our dream themes and images reflect our waking concerns, etc. (Dement, 1976). But there remain a wide variety of approaches to the study of dreaming, each with its own assumptions and methods. While this diversity has yielded a rich and varied literature, it has also produced widely different opinions on some basic issues. For example, are dreams meaningful? The lead article in a recent edition of the newsletter of the Association for the Study of Dreams discusses the issue of meaning in dreams in a very tentative and noncommital tone (Schatzman, 1989). Or take another example: should we make an effort to remember our dreams? While many clinicians encourage or even require their clients to attend to their dreams, some dream theorists take a different view. Francis Crick and Graeme Mitchison have proposed an information processing model of REM sleep that regards dreaming as the phenomenological correlate of the brain's efforts to clear its neural networks of residues of insignificant information. "In this model, attempting to remember one's dreams should perhaps not be encouraged, because such remembering may help to retain patterns of thought which are better forgotten" (Crick \& Mtchison, 1983, p. 114). 
The interest in dreams manifested by the scientific community is mirrored by a corresponding interest on the part of the general public. In 1989 both Newsweek (Begley; Gelman) and Psychology Today (Gackenbach \& Bosveld) featured lead articles on dreams. Even USA Today ran a brief article that looked at the question: "Do your dreams have any meaning?" (July, 1989). The current edition of Books in Print lists 268 books on the topic of dreams (1989, subject guide, 2, pp. 1989-1991). The information proffered by these sources varies from unsupported assertions to polemical arguments to even-handed accounts of current thinking among academiclans and clinicians.

While the current literature on dreams affords us a view of the prevalling thought on dreams within the academic community, it does not afford a similar view of the attitudes and opinions about dreams held by the general public. To what extent have various empirical findings and theoretical developments about dreams permeated the popular mind? And what about the metaphysical issues that are rarely dealt with explicitly in the scientific literature on dreams, but which have been at the core of much of what has been preserved in the historical record--where does the public stand here? Has the question been studied?

\section{STUDIES IN ATTITUDES TOYARD DREAMS}

A search through PsycIkFo and the Soclal Sclences Citation Index reveals only four published articles dealing with attitudes or opinions about dreams. The earliest of these is "Attitudes Toward Dreams, Sex Differences and Creativity" (Domino, 1982). The purpose of the study was to investigate the relationship between attitudes toward dreams and 
creativity. The first obstacle faced by the investigator was the absence of an instrument for measuring attitudes toward dreams. In introducing the study, Domino noted that "the literature is singularly silent on the topic of attitudes toward dreams" (Domino, 1982, p. 114). Domino therefore developed his own Questionnaire About Dreams (QAD) (see APPENDIX A). In reviewing the dream literature Domino came up with 88 attitudinal statements. These were reduced to 34 statements by eliminating redundancies. Respondents to the QAD rate each of the items on a five point Likert scale. Beside statements that are clearly attitudinal, many QAD items are more factual or empirical (e.g., item 1: "Everyone dreams every night").

Domino conducted two studies using the QAD with high school students, from which several interesting themes emerged. Domino found a great deal of diversity in his subjects' attitudes, all response options being chosen by some students (1bid., p. 118). In some cases responses are almost equally split between response options (e.g., 1tems 3 and 31). Despite this diversity, however, on most items one response was endorsed by a substantially larger proportion of respondents than the other options, espectally when responses were tabulated separately for each sex (Domino, 1982, p. 118-119). In many cases the modal response is consistent with the results of laboratory investigations (e.g., 8 and 29). When analyzed separately by sex, females were more in accord with what is empirically known about dreams than were males. For example, 64 percent of females but only 41 percent of males agreed that everyone dreams every night (item 1 ). On only two items do a majority of the responses run counter to empirically established facts (1tems 24 and 27 ). 
Several QAD 1tems deal with theoretical issues that are not subject to strictly empirical solutions. Along with Freud, Jung, and most other psychodynamic theorlsts, Domino's students agreed that dreams are like a window into our subconscious (1tem 22). Nearly all either agreed or were unsure about whether dreams are full of symbols (item 25), and whether understanding one's dreams could make life better (item 16). The majority disagreed with Freud's notion that most dreams have to do with sex (item 4), while the majority agreed that dreams have hidden meanings (item 5 ). Another theme is respondents' essentially positive attitude toward dreams. Over three quarters disagreed with the statement that dreams were basically silly and unimportant (1tem 2), or that the analysis of dreams is a silly thing (item 34). Seventy-elght percent of males and 93 percent of females agreed that they would like to understand their dreams better (item 20), and 70 percent of males and 69 percent of females agreed that they make a special effort to remember their dreams (1tem 17). Most (59 percent of males, 51 percent of females) disagreed with the statement that the dreams that they remember are usually embarrassing (1tem 23).

Domino's data reveal substantial diversity in adolescents' beliefs regarding paranormal issues about dreams. Half of the students agreed that God can speak to us through dreams (1tem 12). One third of the students agreed that dreams often predict the future, while another third were not sure (item 3). On the other hand, only 6 percent agreed that the dead can speak to us through dreams (item 6), while nearly two thirds disagreed. And 30 percent of females, but only 5 percent of males agree that the soul 1s released from the body during dreams and wanders around (1tem 18). 
The second published study dealing with attitudes toward dreams is "Dream Recall and Attitudes Toward Dreams" (Cernovsky, 1984). As Cernovsky noted, several researchers have suggested that "attitudinal variables such as the belief that dreams are meaningful and valuable, interest in dreams, and motivation to recall dreams" may differenttate frequent from infrequent dream recallers as groups (Cernovsky, 1984, p. 911). Evidently unaware of Domino's QAD, Cernovsky wrote that there was "a lack of an instrument to measure attitudes toward dreams" (1bid., p. 911). Cernovsky therefore developed his own instrument, the Attftudes Toward Dreams Scale (ATDS). This scale has 17 true/false items (see APPENDIX B). Because this scale was preceded by another in the context of its administration, the first item was included as a buffer and was not scored. The remaining 16 ttems fall into three subscales. Seven (items $5,6,8,9,10,11$, and 17) deal with the respondents' own attitudes toward dreams; five (1tems $3,4,7,12$, and 15) deal with the respondents' perceptions of the attitudes of significant others toward dreams; and four (1tems 2, 13, 14, and 16) with the respondents' "perceptions of attitudes of other people in general toward dreams or toward individuals who publicly discuss dreams" (tbid., p. 912). Cernovsky administered the ATDS to 46 part-time undergraduate students enrolled in psychology courses (mean age was 25.8 years; 21 females, 24 males, one sex unspectfled). The subjects estimated the number of dreams that they recalled over the past six months. The subscale measuring the person's own att1tudes toward dreams and the 16-1tem scale as a whole were signiftcantly correlated with estimated frequency of dream recall $(r=.32$ and .31 respectively, $p<.05)$. Data regarding the presence or absence of sex differences were not reported. 
The third study, "Attitudes Towards Dreams and MMPI Measures of Psychopathology in Male Chronic Alcoholics," was also published by Cernovsky (1987). Curiously, in this study Cernovsky did not use the ATDS. Rather, he relied on MMPI 1tem 11 whlch reads, "A person should try to understand his dreams and be guided by or take warning from them." This study found no relationship between response to 1 tem 11 and MMPI scales of psychopathology or nightmare frequency. Furthermore, Cernovsky's sample of chronic male alcoholics did not differ significantly from normative data for item 11 (Colligan, et al, 1983).

The fourth and final study concerning attitudes toward dreams, "Interest In Dreams and Dream Recall," was published in 1988 (Robbins \& Tanck). Robbins and Tanck administered a questionnaire which included, among other 1tems, three questions on interest in dreams to 123 undergraduate psychology students. In addition, these students estimated their frequency of dream recall. Because prior research indicates that estimated frequency of dream recall is only modestly related to dream recall as measured by diarles (Antrobus, Dement, \& Fisher, 1964), Robins and Tanck also collected ten-day dream diarles from 89 of the students who completed their questionnaire.

The questions on interest in dreams were: (1) "Have you ever speculated about the possible meaning of one of your dreams?"; (2) "Have you ever discussed one of your dreams with someone else?"; and (3) "Do you have any beliefs or theorles about the meanings of dreams, and, if yes, what are your bellefs? The first two questions had four response options: not that I remember, once or twice, occaslonally, and often. The third question was answered yes or no, with space for an explanation if the yes 
option was chosen. Responses to all items were intercorrelated: speculation and discussion (items 1 and 2 ), $r=.45, p<.01$; speculation and theory (items 1 and 3 ), $r_{p o s}=.45, p<.01$; discussion and theory (1tems 2 and 3 ), $r_{\mathrm{pb}}=.25, p<.05$. Both dream speculation and holding a theory about dreams were positively correlated with estimated dream recall frequency $\left(r=.33\right.$, and $\left.r_{p b s}=.37, p<.05\right)$. Holding a theory about dreams was also positively correlated with the number of nights for which dreams were described in diarles $\left(r_{p b s}=.27, p<.05\right)$.

Consistent with Domino (1982), significant sex differences were found. More women than men reported speculating about their dreams $\left(\chi^{2}=5.79\right.$, $p<.05)$ and discussing their dreams with others $\left(x^{2}=10.79, p<.01\right)$. Io significant sex differences were found for holding a theory about dreams. 


\section{METHODS}

The primary purposes of the present study are (1) to obtain a picture of the knowledge, attitudes, and opinions about dreams of students enrolled in high school social studies and psychology classes and in college-level introductory psychology courses, (2) to investigate the interrelations among these students' responses to questions concerning such knowledge, attitudes, and opinions, and ( 3 ) to develop scales for summartzing respondents' orfentation toward dreams.

Although my initial interest in approaching this toplc was an interest in the knowledge, attitudes, and opinions about dreams prevailing in the general population, the existing research has not proceeded far enough to Justify the effort and expense that would be involved in obtaining such measures from a representative sample of the public. This study extends the current knowledge base by refining an instrument for assessing individuals' orientations toward dreams, and by providing a first look into the interrelations among respondents' knowledge, attitudes, and opinions about dreams.

\section{SUBJECTS}

A total of 394 subjects were recrutted from three populations. The first group was $95 \mathrm{high}$ school students ( 43 male, 52 female) enrolled in various soctal studtes courses and a psychology course at an urban high 
school in Portland, Oregon. These subjects ranged from 15 to 18 years of age, with a mean of 16.6 years and a standard deviation of .9 years.

The second group was 72 community college students (16 male, 56 female). Thirty-eight were enrolled in introductory psychology courses and 34 were enrolled in a Human Development. This community college serves a less urban population than the high school described above, many of the students being drawn from the relatively rural outskirts of the Portland metropolitan area. These subjects ranged from 18 to 50 years of age, with a mean of 26.2 years and a standard deviation of 8.6 years.

The third group was 227 students (100 male, 127 female) enrolled in Introductory psychology courses at Portland State University in downtown Portland. Subjects in this group ranged from 18 to 50 years of age, with a mean of 23.3 years and a standard deviation of 6.6 years.

Both community college and university students received extra credit in return for completing the questionnaire. None of the subjects had studied dreams as a formal part of the courses from which they were drawn.

\section{INSTRUMEIT}

The present study uses a modified form of Domino's QAD for obtaining a descriptive account of students' orientation toward dreams. Only the QAD, among existing instruments, includes a comprehensive array of questions for assessing respondents' knowledge base. The majority of the items on the QAD concern clearly factual issues while the instruments used in the other studies include no items of this nature. The QAD is also the only existing instrument containing questions on theoretical and metaphysical issues. 
In order to make a direct comparison between my data and those reported by Domino (1982), I avoided rewording all but one of the original QAD 1tems. Although several items were not 1deally worded, I felt that the value of being able to make direct comparisons outweighed the minor rewordings I would have preferred. The one exception was item 32 (see APPENDIX A). As originally worded this item is false. I felt it would be much more interesting to determine whether subjects know that external stimuli can be incorporated into dreams than to know whether they falsely belleve that most dreams usually reflect external stlmuli. I therefore reworded tt to "Dreams can reflect what is going on around you while you sleep; for example, a dripping faucet might cause you to dream about water." In developing the original QAD, Domino compiled a pool of attitudinal type statements through a review of the dream literature, and eliminated redundancies through a sertes of logical analyses (Domino, 1982, p. 114). This procedure suggests good content validity for the QAD. Ievertheless, I extended the QAD by including a few additional questions on content not Included by Domino. First, I added an item to assess the prevalence of lucid dreaming (1.e., awareness that one is dreaming) (APPENDIX C, 1tem 38 ). While brief references to lucid dreaming can be found as early as the fourth century B.C. (Aristotle, 1952), and instructions for inducing lucidity during dreaming date from the middle of the last century (Saint-Denys, 1867), it was not unt1l 1980, that the phenomenon was empirically established (LaBerge, 1980). Wo published studies assess the prevalence of lucid dreaming.

Second, Informal discussions with friends have convinced me that many people still believe that even dreams that seem to last a long time 
actually occur instantaneously, an idea first proposed by Maury (1861/1878), but discredited since the discovery of REM sleep. I therefore added an item to the QAD for assessing the prevalence of this bellef (APPEIDIX C, item 35).

Third, I added two 1tems on theoretical 1ssues. QAD 1tem 5, "Dreams have hidden meanings," is ambiguous. An affirmative response could signify an acceptance of Freud's idea of censorship, or it could simply denote a bellef that dreams express meanings allegorically. I have added an item to distinguish between these two interpretations ("Dreams are deliberately disguised to hide their true meanings from us," APPENDIX C, item 36). Also, because of the widespread popularity of Jung's work, I added an Item reflecting his main tenet of dream function: "The purpose of dreams is to restore balance to the mind" (APPENDIX C, item 37 ).

Even with these additions, however, it is quite possible that some widely held beliefs or opinions about dreams might not be tapped by any QAD items. Therefore, I also added an open-ended question modified from Robbins and Tanck (1988): "Do you have any beliefs or theories about dreams, and if yes, what are they?" (APPENDIX C, item III). Response to this item will be examined to determine whether any significant issues are mentioned which are not already included in the QAD.

Finally, to strengthen the QAD's strictly attitudinal component, I added four more items. The first two are from Robbins and Tanck: "Have you ever speculated about the possible meaning of one of your dreams?" and "Have you ever discussed one of your dreams with someone else?" (APPENDIX C, Items I and II). The others are "Have you ever read a book or magazine article about dreams?", and "If yes, how many?" (APPEIDIX C, 1tem IV). 
Scales

In analyzing and summarizing responses, I tentatively grouped most items into four subscales (see APPEXDIX D). Items $1,7,8,9,10,11,13$, $14,15,19,21,24,26,27,29,30,32$, and 35 constituted the provisional Factual scale; items $4,5,16,22,25,36$, and 37 are all theoretical in nature and made up the initial Psychodynamic Orientation scale; items 3, 6, 12 , and 18 are all strictly metaphysical and comprise the proposed Paranormal Orientation scale; and 1tems I, II, III, IV, $2,17,20,23,33,34$, and 38 made up the inftial Attitude scale.

The format of the QAD yields an item score of "5" when a subject strongly disagrees and a score of "1" when a subject strongly agrees. For computing scale scores true Factual scale items and all positively worded 1tems from other scales were reversed ( 1 to $7,10,15$ to 18,20 to 22,25 , $26,32,33,36$ to 38 ).

The construct validity of the scales was evaluated by two methods. First, a factor analysis was performed on each scale. It was assumed that each scale should present a single primary factor. Second, a matrix of correlations of individual items with each of the scales was examined. Ideally, items that have been correctly assigned should correlate more strongly with their own scales than with other scales (Loevinger, Gleser, \& DuBois, 1953). This method is an approach to what Campbell and Fiske (1959) have referred to as discriminant validation.

Scales were also evaluated for internal consistency by computing Cronbach's alpha coefficient. Alpha is the mean split-half correlation of all possible splittings of a test, and constitutes a conservative estimate of the reliability coefficient (Cronbach, 1951). A large alpha for any 
scale would be an indicator that it is reliably measuring a single factor. A moderate alpha would suggest the presence of more than one factor, while a very low alpha would suggest either that the items are not appropriately grouped as a scale, or that the construct being measured does not represent a coherently organized unitary variable within the population being studied. 


\section{RESULTS AND DISCUSSION}

\section{COMPARISON OF HIGH SCHOOL SAMPLE RESPONSES}

A comparison of individual item responses from my high school sample with those reported by Domino (1982) reveals both interesting similarities and differences. Domino collapsed his original data into three response categories for presentation, reporting both "agree" and "strongly agree" combined as "agree" and "disagree" and "strongly disagree" combined as "disagree" (ibid., p. 115). The third category was "not sure." Comparing data at this level, the most obvious similarity occurs in subjects' modal responses. My subjects' modal responses were the same as Domino's for both sexes on $75 \%$ of the original QAD items. The exceptions were items 1,25 , 26 , and 31, where modal responses differ for males only; 1tem 33 which differed for females only; and items $3,12,16$, whlch differed for both sexes. When responses for both sexes are combined, modal responses differ only for three $\mathrm{QAD}$ items $(12,16,25)$. This strong tendency for agreement in modal responses (91\%), despite our data coming from different geographical regions and being collected at least 8 years apart, suggests at least moderate stability in orientation toward dreams among high school students.

The first item on which overall modal response differed was item 12 , "God can speak to us through dreams." Domino's male subjects tended to agree (59\%) with this statement, and the bulk of those remaining (29\%) were 
not sure (see TABLE I). The males in my high school sample were less confident ( $37 \%$ agreeing and $44 \%$ not sure). The same negative shift occurred in female responses: in Domino's sample $40 \%$ agreed, $51 \%$ were not sure, and 9\% disagreed, while my female subjects were about equally divided.

\section{TABLE I}

HIGH SCHOOL STUDENTS' RESPONSES TO ITEM 12:

"GOD CAI SPEAK TO US THROUGH DREAMS."

\section{Domino Governale}

$\begin{array}{lrrl}\text { agree } & 59 \% & 37 \% & \begin{array}{l}\text { male } \\ \text { female }\end{array} \\ & 40 \% & 33 \% & \text { male } \\ \text { not sure } & 29 \% & 44 \% & \text { female } \\ & 51 \% & 33 \% & \text { male } \\ \text { disagree } & 12 \% & 19 \% & \text { female }\end{array}$

The other two 1tems on which overall modal responses differed concerned respondents' psychodynamic orientation. The majority of Domino's subjects were not sure whether "understanding one's dreams can make your life better" (males $54 \%$, females $57 \%$ ), while most of those remaining agreed (males 43\%, females 39\%). My subjects were more positive (see TABLE II).

\section{TABLE II}

HIGH SCHOOL STUDENTS' RESPOHSES TO ITEY 16: "UNDERSTANDING ONE'S DREAKS CAN MAKE YOUR LIFE BETTER."

Domino Governale

$\begin{array}{lrrl}\text { agree } & 43 \% & 56 \% & \text { male } \\ & 39 \% & 48 \% & \text { female } \\ \text { not sure } & 54 \% & 35 \% & \text { male } \\ & 57 \% & 40 \% & \text { female } \\ \text { disagree } & 3 \% & 9 \% & \text { male } \\ & 4 \% & 12 \% & \text { female }\end{array}$


Mast (males 56\%, females 48\%) agreed with 1 tem 16 while the bulk of those remaining were not sure.

Most of Domino's male respondents $(58 \%)$ were not sure whether "Dreams are full of symbols" (item 25), while nearly all of the rest (40\%) agreed. The opposite was true of my male respondents: $54 \%$ agreed while $35 \%$ were not sure. Both Domino's and my female respondents tended to agree with item 25 (49\% and 69\% respectively) while most of those remaining were unsure (45\% and $23 \%$ respectively). Responses for males were more affirmative, and both sexes were more definite, for my sample than for Domino's. It is not possible to say whether the discrepancles on these three items are due more to regional or cohort differences.

\section{TABLE III}

HIGH SCHOOL STUDENTS' RESPONSES TO ITEY 25:

"DREAKS ARE FULL OF SYMBOLS."

\section{Doming Governale}

$\begin{array}{lrrl}\text { agree } & 41 \% & 54 \% & \text { male } \\ & 49 \% & 69 \% & \text { female } \\ \text { not sure } & 58 \% & 35 \% & \text { male } \\ & 45 \% & 23 \% & \text { female } \\ \text { disagree } & 1 \% & 12 \% & \text { male } \\ & 6 \% & 8 \% & \text { female }\end{array}$

Despite the great similarity in modal responses, Domino's data and mine differ markedly in the extent of sex differences. Using chi square analyses, Domino found sex differences on 20 out of the 33 QAD 1tems for which data were reported, 8 of these at the .05 level (1tems $3,7,9,10,21$, and 23 ) and the remaining 12 at the .01 level (items $1,5,8,12,13,15,18$, $20,27,29,31,32$, and 33). (See APPEIDIX A for original QAD items.) 
Among the 32 comparable items (\#32 was reworded) I found significant $(p<.05)$ sex differences on only 6 items $(11,12,20,21,29$, and 34$)$, on two of which (\#11, \#34) Domino found no sex difference. Assuming part of this discrepancy to be due to my smaller sample size (95 subjects as opposed to Domino's 196), I looked for differences at the .10 level. This added three more 1 tems $(3,23$, and 31$)$, all of whtch were among the items for which Domino found differences. This still leaves 8 items $(1,5,8,13$, 15, 18, 27, and 33) for which Domino found differences at the .01 level for which I found no difference at even the .10 level. Th1s discrepancy cannot be accounted for by differences in sample size. Again, however, it is not possible to determine the relative contributions of regional and cohort differences.

\section{SCALE DEVELOPKENT}

The foregoing analysis of similarities and differences between Domino's data and mine reveals the need for a method of summarizing responses in two ways. First, a simple ttem-by-item comparison is inelegant and confusing: one does not come away with a coherent sense of respondents' orientations toward dreams. Second, without scales for summarizing responses it would be difficult to say anything meaningful about the reliabllity or validity of the measures obtained.

Factor analyses, alpha coefficlents, and correlation matrices were generated using SPSS- $X$. Desplte having an insufficient number of respondents to perform strong factor analysis on the whole extended QAD (43 items), such an analysis was attempted to see what it might reveal. Fourteen principal components were extracted with eigenvalues over 1 , 
requiring 78 iterations for convergence with vartmax rotation. Examination of a scree plot revealed that eigenvalues virtually leveled out after the first six factors. The first six factors accounted for $39.2 \%$ of the variance. The gain in variance accounted for by each of the 8 additional factors ran from $3.3 \%$ to $2.3 \%$. The factor analysis was thus rerun to extract only 6 factors. The resulting grouping of items into six factors was difficult to characterize meaningfully. Most of the factors could not be named descriptively based on an examination of ttem content. The factor analysis was rerun using oblimin rotation and the items grouped together in the same fashton. Two explanations accounting for this disarray emerged after further analysis and will be discussed at the points at which they emerged.

Items were then divided Into provisional scales as described above under Methods. The internal consistency and factor analyses showed that the inftial groupings of 1tems made on the basis of item content was substantially appropriate. Some changes were made in each of the scales, however, and since these changes were made in stages, and since most changes affected two scales simultaneously, the following description will necessarlly skip around some. Once the final form of a scale has been described, reference will be made to the appropriate appendix.

A factor analysis of 1tems 3,6,12, and 18 (provisional Paranormal Orientation scale) and 1tems $4,5,16,22,25,36$, and 37 (provisional Psychodynamic Orientation scale) was run. Three coherent factors emerged. The first included items $5,16,22,25$, and 37 (factor loadings ranging from .79 for 1tem 22 to .48 for 1 ten 37 ). All of these items were from the provisional Psychodynamic Orientation scale. Items 3, 6, 12, and 18 (from 
provistonal Paranormal Orientation scale) comprised the second factor (loadings ranged from .71 for 1tem 6 to .59 for item 12). Only 1tems 4 ("Most dreams have to do with sex") and 36 (Dreams are delfberately disguised to hide their true meanings from us") had substantial loadings (.76 and .70 respectively) on the third factor (the next highest loading was .27 for item 37). These items are both specific to psychoanalytic theory and can be constdered a Freudian subscale. Ve will return to this later. Rellability analysis supported the above groupings. The provisional Paranormal Orfentation showed an alpha of .66 with all 1tems correlating positively. The provistonal Psychodynamic Orientation scale had an alpha of .64 , but 1tems 4 and 36 correlated with the scale at only .11 and .12 respectively. When they were deleted from the scale alpha rose to .73 .

A factor analysis was then performed on ttens I, II, III, IV, 2, 17, 20, $23,33,34$, and 38 which comprised the initial Attitude scale. (Iten IV was broken down into two: (a) "Have you ever read a book or magazine article about dreams?" and (b) "If yes, how many?") Four factors emerged. Items I, II, III, 2, 17, 20, 34 all loaded most strongly on the first factor (loadings ranged from a high of .73 for 1 tem I to .47 for item III). Items IV(a) and IV (b) both loaded substantially on the first factor (.54 and .58 respectively), but loaded even more strongly as a separate factor (.72 and .71 respectively). The third factor had only two substantial loadings: item 23 ("The dreams I remember are usually embarrasstng") and 1tem 38 ("In my dreams I sometime know that I am dreaming"). Examination of the full correlation matrix showed that 1tem 23 correlated most strongly (.29--there were no close seconds) with 1tem 4 ("Most dreams have to do with sex"). Item 23 was moved to the Freudian subscale (with items 4 and 36 ) where 
further analysis revealed the three items to load on one factor. The alpha for this subscale, however, is only .41 (APPENDIX E).

Item 38 correlated most strongly with items 26 (.25) and IV (b) (.24), Interestingly, these three items comprised one of the six factors extracted when all 43 1tems were analyzed together. Item 26 reads "It is possible to decide before falling asleep, what one will dream about." I think that it is no colncidence that one of the main issues in mast of what has been written on lucid dreaming concerns controlling the course of one's dreams (for example, LaBerge, 1985). Items 26 and $38 \mathrm{might}$ form the core for a Lucidity scale. These items together yleld an alpha of .41 (see APPENDIX E). It is intersting to speculate on the correlation of item IV(b) (number of books and articles on dreams read) with 1tem 38: perhaps those who find themselves aware of their state during their dreams are inspired to study about dreaming.

Only item 33 ("In my religion, dreams are very important") loaded substantially on the fourth factor extracted. Examination of the correlation matrix revealed that item 33 correlated most strongly with item 12 ("God can speak to us through dreams"). Item 33 was moved to the Paranormal Orientation scale where it was found to load on the same factor, and where it ralsed the alpha coefficient to .66 (see APPENDIX E).

The Attitude scale was reanalyzed without 1tems 23,33 , or 36 . This left two factors, with only items IV(a) and IV(b) loading substantially on the second factor. The reliability analysis produced an alpha coefficient of .77 , and revealed that item IV (b) (number of books and articles read) was the only 1tem on the scale detracting from the magnitude of alpha. Item IV (b) was removed and the resulting scale now produced only one 
factor and had an alpha coefflcient of .78. The second factor had been an artifact of ttem IV(b)'s logical dependence on item IV(a) and their strong resulting intercorrelation (.77). More is gained than lost by its exclusion from the attitude scale. It is interesting to speculate that both items IV (a) and (b) may reflect respondents' general inclination to read as much as their specific interest in dreams.

Items $1,7,8,9,10,11,13,14,15,19,21,24,26,27,29,30,32$, and 35) made up the hypothesized Factual Knowledge scale. These 1tems had been orfginally grouped together because they all concern issues that have been empirically investigated and have well established, relatively unambiguous answers. Item 28 ("Remembering one's dreams is a sign of a good imagination") was not included in the factual scale because the relationship previously thought to exist between dream recall and creativity has recently been called into question by a study in which the apparent relationship disappeared when verbal fluency was controlled for (Wood, Sebba, \& Dom1no, 1989-90). Item 31 ("Dreams are like you're personal1ty; if you're a happy person your dreams will be happy") was also omitted, primarily due to its ambiguity. Although it has been demonstrated that one's style of dreaming (e.g., levels of guilt and anxiety) is consistent with one's style of waking fantasy (Starker, 1982, chap. 5), there is much more to personality than the nature of one's daydreams. Also, while it has been shown that several aspects of dream content and emotion tend to be consistent with long term personality characteristics, there are also circumstances under which drean content typically complements or compensates for what is happening in one's waking experience (Cartwright, 1978, chap. 6). 
A factor analysis was run on the provisional Factual scale which produced seven factors and an alpha of .54 . Item 26 ("It is possible to decide before falling asleep, what one will dream about") was the only item with a strong loading on factor seven. Because of this, and because it had already been found to correlate more strongly with item 38 than any other (see Lucidity subscale above), it was removed from the factual scale. The reliability and factor analyses were rerun, resulting in an alpha of .54 and six factors which were scrutinized to see what sense could be made of them.

Items 1 ("Everyone dreams every night"), 8 ("Some people never dream"), and 29 ("People born blind do not dream") comprised the first factor. These 1 tems all concern who dreams. They produced an alpha coefficient of .55 .

Items 7 ("Dreams can result in useful inventions"), 10 ("Dreams can be used to create a poem, a painting, or a work of art"), 11 ("Bizarre dreams are a sign of mental 1llness"), and item 32 ("Dreams can reflect what is going on around you while you sleep; for example, a dripping faucet might cause you to dream about water") formed the second factor. The first two items directly, and the third tangentially, are related with creativity in dreams. Item 32 is more concerned with the influence of contemporaneous external events on dream content. Together they produced an alpha coefficient of .55 .

The third factor was composed of items 15 ("Dreams reflect goals we wish to acheive") and 21 ("People usually dream about what they are concerned with in their lives"). Both items refer to dream content reflecting inner concerns. Together they yield an alpha of .57 . 
Items 13 ("What we dream about is usually what happened the day before"), 14 ("Old people often dream about dying"), and 19 ("Most dreams occur because of what we eat (as for example, indigestion)") comprised the fourth factor. Items 13 and 14 deal with external circumstances Influencing dream content, while item 19 concerns the influence of a biological process on dreams. These items produce an alpha of 39.

Items 9 ("Dreams occur in black and white (rather than in color")), 27 ("Most dreams 1nvolve activities and settings that are very unusual and fantastic"), and 35 ("Even dreams that seem to last nearly an hour happen in only an instant") formed the fifth factor. These 1tems concern the relative continuity of cognitive processes and content between waling and dreaming. This factor produced an alpha of only .29 .

The sixth and final factor included items 24 ("The more soundly we are asleep, the more likely we are to dream") and 30 ("Only humans dream; dogs and other animals do not dream"); they produced an alpha of .25.

Vhen I originally included item 24 in the provisional Factual scale, I was thinking of it in terms of sleep stages and coded it as false. It occurred to me that the wording of the item is actually ambiguous, and that since a transition to REM sleep becomes increasingly probable as stage four sleep proceeds, a thoughtful and informed person might answer it as true. Examining the correlation matrix I found that 1tem 24 correlated most strongly (-.24) with item 18 ("During dreams the soul is released from the body and wanders around") from the Paranormal scale. Because of tts ambiguity, because I could make no sense of It's correlations with item 18 or of its weaker (.15) correlation with item 30 , and because the low alpha 
1t produces when grouped with 1 tem 30 , I dropped item 24 from the factual scale. This still left six factors and an alpha of .54 .

My next step was to construct and examine a correlation matrix of each of the remalning Factual scale items with each of the scales. I found that items 7 ("Dreams can result in useful inventions") and 10 ("Dreams can be used to create a poem, a painting, or a work of art") correlated more strongly with the Attitude scale ( .39 and .30 respectively) than with the corrected Factual scale (.23 and .25). These 1tems can be conceved of as representing the idea that dreams can be useful in a practical, even economic, sort of way. It would make sense to characterize this as being a positive attitude about dreams. I thus moved items 7 and 10 to the Attitude scale and reanalyzed 1t. These items slightly increased the alpha coefficient of that scale from .78 to .80 (see APPENDIX E). The resulting scale still produced only factor above the scree.

Examination of the correlation matrix also revealed that items 15 ("Dreams reflect goals we wish to achieve") and 21 ("People usually dream about what they are concerned with in their l1ves") correlated more strongly with the Psychodynamic scale (.34 and .39 respectively) than with the corrected Factual scale (.15 and .20). These items are not only consistent with, but are implied by a strong psychodynamic orientation. When added to the Psychodynamic scale they increased the alpha coefficient from .73 to .76 . The resulting scale st1ll produced only one factor (see APPERDIX E).

Rerunning the factor analysis without 1tems 7, 10,15, and 21 , resulted in an alpha of only .46, and still produced five factors, some of which continued to defy coherent interpretation. I had expected that this scale 
would form a single hierarchically organized factor reflecting how much factual information respondents posses about dreams. This, however, was not the case. It may be that in our culture most people's knowledge about dreams is relatively unstructured. What my subjects knew about external influences on dream content was unrelated to their knowledge of who dreams $(r=.02, p>.10)$ or their knowledge of the continuity of dreaming and waking cognition $(r=.06, p>.10)$; and only a slight negative correlation was found between their knowledge of who dreams and their knowledge of the continuity of dreaming and waking cognition $(r=-.11, p<.05)$. Perhaps this fragmented structure in factual knowledge about dreams should have been expected. After all, the study of dreams and dreaming is not a part of the formal curriculum in our public schools, and is probably not included in most private school curricula efther. Perhaps in a culture where dreams are regarded more seriously than in ours, where thinking about dreams is a part of one's herttage, a single hierarchically organized factor would be obtained. Be this as it may, the rellabiltty of the Factual Knowledge scale has not been demonstrated.

In an attempt to derive some coherent subscales I found that removing Items 11 and 32 resulted in four interpretable factors. Examination of the scree plot suggested allowing only three factors, which brought two of the four together and resulted in three interpretable factors. The first is composed of 1tems 1 ("Everyone dreams every night"), 8 ("Some people never dream"), 29 ("People born blind do not dream") and 30 ("Only humans dream; dogs and other animals do not dream"). These items comprise the Who Dreams subscale; together they yield an alpha of .58 . 
Items 13, 14, and 19 (see factor four above) comprise the second factor and might make up the core of a subscale dealing with the influence of external circumstances influencing dream content.

Items 9,27 , and 35 (see factor five above) might form the basis of a subscale dealing with the relative similarity of dream cognition with waking cognition.

Now that the scales have been described, we can return to the question of why the initial factor analysis on the whole extended QAD was difficult to characterize. Two main causes can be identified, the first of which we can discuss now, and the second of which will be discussed when we have described the interrelations between the scales. The first concerns the lack of coherent structure in responses to Factual Knowledge scale items. Because respondents' knowledge base is so fragmented, intercorrelations between factual knowledge Items was weak and inconsistent. As often as not, these items correlated as strongly with items on the other scales as with other 1tems on the Factual scale. For example, item 32 ("Dreams can reflect what is going on around you while you sleep...") correlated more strongly with item 10 ("Dreams can be used to create ... a work of art") from the Attitude scale and 1tems 21 ("People usually dream about what they are concerned with in their lives") and 22 ("Dreams are like a window into our subconscious") from the Psychodynamic scale than it did with any other 1tems on the Factual scale.

\section{SUMMARY OF STUDENTS' ORIEHTATIOHS TOWARD DREAYS}

The value of our scales becomes evident when we seek to characterize respondents' orientations toward dreams. Students in my sample have an 
overall positive attitude or valence toward dreams. The Attitude scale has a possible range from a low of 10 to a possible bigh of 42 (see TABLE IV) and a midpoint of 26 . Responses ranged from a low of 18 to a high of 42 , with a mean of 34 and a standard deviation of 5. All response options were chosen by some students. This positive attitude was demonstrated by students' responses to all Att1tude scale 1tems. E1ghty-seven percent of respondents agreed or strongly agreed that they would like to understand their dreams better (item 20). In contrast, only $4 \%$ agreed or strongly agreed that "dreams are basically sllly and not important" (1tem 2).

\section{TABLE IV}

\section{ATTITUDE SCALE SUMMARY}

$\begin{array}{cccc}\text { mean } & \text { s.d. } & \text { min. } & \text { m } \\ 34 & 5 & 18 & 4 \\ 4.1 & .9 & 1 & 5 \\ 3.7 & .8 & 1 & 5 \\ 4.1 & .7 & 1 & 5 \\ 3.5 & 1.1 & 1 & 5 \\ 4.3 & .8 & 1 & 5 \\ 4.2 & .9 & 1 & 5 \\ 3.1 & .9 & 1 & 4 \\ 3.3 & .7 & 1 & 4 \\ 1.8 & .4 & 1 & 2 \\ 1.6 & .5 & 1 & 2\end{array}$

Scoring for negative 1 tems $(2,34)$ from 1 = Strongly Disagree to 5 = Strongly agree; the opposite is true for positive five-point items $(7,10,17,20)$. Items 39 and 40 score from 1 = not that I remember, to $4=$ often. Items 41 and $42: 1=$ no, $2=$ yes. 
The more behavioral items also reflected this positive valence. For example, only $11 \%$ indicated that they have never or have only once or twice discussed their dreams with someone else, whereas $47 \%$ indicated that they do so occasionally, and another $42 \%$ indicated that they do so often.

Scores on the Psychodynamic Ortentation scale ranged from a low of 14 to a high of 34 , with a mean of 26 and a standard deviation of 4 (see TABLE V). Responses show that the students in my sample belleve that dreams are meaningfully related to the mind's psychic economy. For example, 87\% agreed or strongly agreed that "People usually dream about what they are concerned with in their 11ves," (1tem 21) and 79\% agreed or strongly agreed that "Dreams are like a window into our subconscious" (item 22). They were less sure, however, about what role dreams might play. For example, the modal response $(50 \%)$ to 1tem 37 ("The purpose of dreams is to restore balance to the mind") was "not sure."

\section{TABLE V}

\section{PSYCHODYNAKIC ORIENTATION SCALE SUMKARY}

mean s.d. min max item

$26414 \quad 34$ Full Scale (range: 7 to 35 ; midpoint: 21 )

$\begin{array}{lllll}3.7 & 8 & 1 & 5 & 5 .\end{array}$

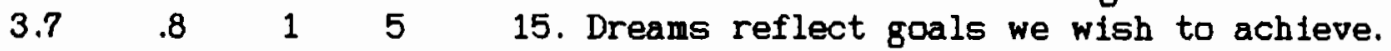

$\begin{array}{lllll}3.4 & 9 & 1 & 5 & 16\end{array}$. Understanding one's dreams can make your life better.

$\begin{array}{lllll}4.1 & 7 & 1 & 5 & 21 .\end{array}$ concerned with in their lives.

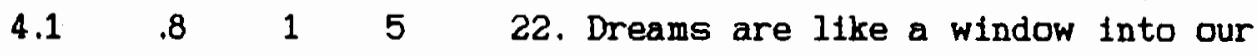
subconsctous.

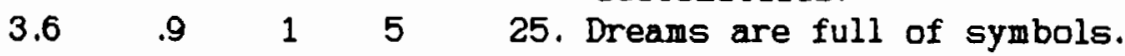

$\begin{array}{lllll}3.2 & .8 & 1 & 5 & 37\end{array}$. The purpose of dreams is to restore balance to the mind.

Scoring: 1 = Strongly Disagree; 5 = Strongly agree. 
Although respondents in my sample were moderately inclined toward a general psychodynamic orientation, they were distinctly disinclined toward a Freudian viewpoint (see TABLE VI). The overwhelming majority (70\%) disagreed or strongly disagreed with Item 4 ("Kost dreams have to do with sex"), and none strongly agreed. Likew1se, only 9\% agreed or strongly agreed that "dreams are deliberately disguised to hide their true meanings from us" (item 36), whereas 55\% disagreed or strongly disagreed.

\section{TABLE VI}

\section{FREUDIAN ORIENTATION SCALE SUMMARY}

\begin{tabular}{|c|c|c|c|c|}
\hline 7 & 4 & 3 & 13 & Full Scale (range: 3 to 15; midpoint: 9) \\
\hline 2.3 & .8 & 1 & 4 & 4. Most dreams have to do wtth sex. \\
\hline 2.4 & .9 & 1 & 5 & $\begin{array}{l}\text { 23. The dreams I remember are usually } \\
\text { embarrassing. }\end{array}$ \\
\hline 2.4 & .9 & 1 & 5 & $\begin{array}{l}\text { 36. Dreams are deliberately disguised to hide } \\
\text { their true meanings from us. }\end{array}$ \\
\hline
\end{tabular}

Scoring: 1 = Strongly Disagree; 5 = Strongly agree.

The respondents in my sample were also not inclined toward a supernatural understanding of dreams (see TABLE VII). Overall Paranormal Orientation scale responses ranged from a low of 5 to a high of 23 with a mean of 12 and a standard deviation of 4 . At their most supernatural, respondents were divided over whether "God can speak to us through dreams" (item 12): $31 \%$ agreed or strongly agreed, $37 \%$ were not sure, and $32 \%$ disagreed or strongly disagreed. At the other end of the spectrum, only $6 \%$ agreed or strongly agreed that "dreams are a way by which the dead speak to us" (item 6), while $72 \%$ disagreed or strongly disagreed. 
TABLE VII

PARANORMAL ORIENTATION SCALE SUMMARY

\begin{tabular}{|c|c|c|c|c|}
\hline 12 & 4 & 5 & 23 & Full Scale (range: 5 to 25; midpoint: 15) \\
\hline 2.8 & 1.0 & 1 & 5 & 3. Dreams often predict the future. \\
\hline 1.9 & 1.0 & 1 & 5 & $\begin{array}{l}\text { 6. Dreams are a way by which the dead speak } \\
\text { to us. }\end{array}$ \\
\hline 3.0 & 1.2 & 1 & 5 & 12. God can speak to us through dreams. \\
\hline 2.2 & 1.1 & 1 & 5 & $\begin{array}{l}\text { 18. During dreams the soul is released from } \\
\text { the body and wanders around. }\end{array}$ \\
\hline 2.4 & 1.1 & 1 & 5 & $\begin{array}{l}\text { 33. In my religion, dreams are very } \\
\text { important. }\end{array}$ \\
\hline
\end{tabular}

Scoring: 1 = Strongly Disagree; 5 = Strongly agree.

The Lucidity scale (see TABLE VIII) provides some interesting new information. Although respondents were roughly split about whether one could decide in advance what to dream about (1tem 26:38\% agree / strongly agree, 32\% not sure, $30 \%$ disagree / strongly disagree), they indicated that in thetr own dreams, they are sometimes aware that they are dreaming (item 38: 72\% agree / strongly agree, 13\% not sure, 14\% disagree / strongly disagree). This 1s, to my knowledge, the first time that the prevalence of luctd dreaming has been assessed.

\section{TABLE VIII}

LUCIDITY SCALE SUMMARY

$\begin{array}{llllll}\text { mean } & \text { s.d. min. max. } & \text { Item } & \\ 7 & 2 & 2 & 10 & \text { Full Scale (range: } 2 \text { to } 10 \text {; midpoint: } 6 \text { ) } \\ 3.1 & 1.0 & 1 & 5 & \begin{array}{l}26 . \\ \text { It is posstble to decide before falling } \\ \text { asleep, what one will dream about. }\end{array} \\ 3.8 & 1.1 & 1 & 5 & \begin{array}{l}\text { 38. In my dreams I sometimes know that I am } \\ \text { dreaming. }\end{array}\end{array}$

Scoring: 1 = Strongly Disagree; 5 = Strongly agree. 
Respondents' standing on the Factual scale is a bit more difficult to characterize due to the lack of consistency from one topic to another. Overall, they were more correct than incorrect (mean, 43; standard deviation, 4; range, 32 to 54$)$, though this varied from one subscale to another (see TABLE IX). Students did best on the Who Dreams subscale

\section{TABLE IX}

FACTUAL KMOWLEDGE SCALE SUMMARY

\begin{tabular}{|c|c|c|c|c|}
\hline 43 & 4 & 32 & 54 & Full Scale (range: 12 to 60 ; midpoint: 36 ) \\
\hline 16 & 3 & 9 & 20 & Who Dreams Subscale (midpoint: 12) \\
\hline 4.1 & 1.1 & 1 & 5 & 1. Everyone dreams every night. \\
\hline 4.0 & 1.0 & 1 & 5 & 8. Some people never dream. \\
\hline 4.1 & .9 & 1 & 5 & 29. People born blind do not dream. \\
\hline 4.1 & 1.0 & 1 & 5 & $\begin{array}{l}\text { 30. Only humans dream; dogs and other } \\
\text { animals do not dream. }\end{array}$ \\
\hline 10 & 2 & 6 & 15 & External Influences Subscale (midpoint: 9) \\
\hline 3.1 & 1.0 & 1 & 5 & $\begin{array}{l}\text { 13. What we dream about is usually what } \\
\text { happened the day before. }\end{array}$ \\
\hline 3.1 & .6 & 1 & 5 & 14. Old people often dream about dying. \\
\hline 3.7 & .9 & 2 & 5 & $\begin{array}{l}\text { 19. Most dreams occur because of what we ea } \\
\text { (as for example, indigestion). }\end{array}$ \\
\hline 9 & 2 & 3 & 14 & Cognitive Processes Subscale (midpoint: 9) \\
\hline 3.7 & 1.1 & 1 & 5 & $\begin{array}{l}\text { 9. Dreams occur in black and white (rather } \\
\text { than in color). }\end{array}$ \\
\hline 2.8 & 1.1 & 1 & 5 & $\begin{array}{l}\text { 27. Kost dreams involve activities and } \\
\text { settings that are very unusual and } \\
\text { fantastic. }\end{array}$ \\
\hline 2.5 & .9 & 1 & 5 & $\begin{array}{l}\text { 35. Even dreams that seem to last nearly an } \\
\text { hour happen in only an instant. }\end{array}$ \\
\hline 4.3 & .8 & 1 & 5 & $\begin{array}{l}\text { 11. Bizarre dreams are a sign of mental } \\
\text { illness. }\end{array}$ \\
\hline 3.7 & .9 & 1 & 5 & $\begin{array}{l}\text { 32. Dreams can reflect what is going on } \\
\text { around you while you sleep; for example, } \\
\text { a dripping faucet might cause you to } \\
\text { dream about water. }\end{array}$ \\
\hline
\end{tabular}

Scorlng: True 1tems (1, 32) are scored from 1 for strongly disagree to 5 for strongly agree; all other items are false and score oppositely. 
(items $1,8,29,30$ ), with a mean score of 16 (s.d. 3), a low score 9, and a high of 20; on all items the modal response was correct. Students were unsure about external influences on dreams. The External Influences subscale mean was 10 (s.d. 2), and the range was from 6 to 15 . On item 13 ("What we dream about is usually what happened the day before"), responses were about equally split between agree $(30 \%)$, not sure $(30 \%)$, and disagree (32\%), with very few subfects strongly agreeing (3\%) or strongly disagreeing (5\%). On 1tem 14 ("Old people of ten dream about dying"), most respondents knew that they didn't know (75\% not sure). Most subjects did know that dreams are not caused by indigestion, 58\% disagreeing or strongly disagreeing with item 19 , and no subjects strongly agreeing.

Respondents' performance on the Continuity of Cognitive Processes subscale was more varled. They did best on 1tem 9 , only $12 \%$ belleving that dreams occur in black and white, while $61 \%$ disagreed or strongly disagreed. They did worst on item 35 , fully $51 \%$ agreeing or strongly agreeing that dreams occur instantaneously, while most of the rest (37\%) were not sure.

\section{Age, Sex, and School Differences}

A correlation matrix was examined for any age effects. There were several statistically significant but weak correlations between items and age. All three Freudian scale items $(4,23,36)$ were negatively correlated $(r=-.10,-.08$, and -.09 respectively, $p<.05)$ with age. As a result, the Freud scale 1s significantly correlated with age $(r=-.13, p<.01)$. Apparently, younger students are slightly more likely to dream about sex (1tem 4), to be embarrassed by their dreams (itell 23), and to belleve that their dreams are deliberately disguised (item 36). 
Items 8 and 29 also showed small negative correlations with age $c r=-.13, p<.01$, and $-.10, p<.05$ respectively. This was reflected in a similar correlation in the Vho Dreams subscale $(r=-.12, p(.01)$. Younger students are apparently a little better informed about the universality of dreaming.

Although there were no other significant correlations at the level of scales, several other individual items showed significant correlations with age. Items 15,18 , and 20 were negatively correlated with age $(r=-.13$, -.11 , and -.08 respectively). None of these appear to be particularly meaningful. Items $24,27,28,39$, and 43 , were all positively correlated with age. It makes sense that the older students would have read more about dreams (item $43, r=.10$ ). It appears that they are also slightly more inclined to speculate about the meanings of their dreams ( 1 tem 39 , $r=.14)$. The two 1tems that correlated the strongest $(r=.20, p<.001)$ with age are ttems 27 ("Mast dreams involve activities and settings that are very unusual and fantastic") and 28 ("Remembering one's dreams is a slgn of a good imagination"). An explanation for these correlations is not evident.

Sex differences for scales and items were examined through two-tailed t-tests for differences between means. All reported $t$ values are based on separate variance estimates (see TABLE $X$ ). Significant sex differences were found in Attitude, Psychodynamic, and Freudian scales. Women scored higher on both the Attitude and Dynamic scales than did men, while the opposite was true for the Freudian scale. On half of the Attitude scale items women scored significantly higher than men (1tem $2, p<.01$; 1 tems $34,39,40$, and $41, p(.001)$. Women were less likely to regard dreams as 
silly (1tems 2 and 34 ), and were more prone toward discussing, speculating, and holding beliefs or theorles about dreams (items $39,40,41$ ).

TABLE X

SEX DIFFEREICES IN SCALE SCORES

$\begin{array}{llllll}\text { Scale } & \text { Sex } & \text { Kean } & \text { S.D } & \text { tralue } & \text { Significance } \\ \text { ATTD } & \text { F } & 34.4 & 4.5 & 3.98 & p<.001 \\ & \text { H } & 32.5 & 4.8 & & \\ \text { DYII } & \text { F } & 26.2 & 3.9 & 2.05 & p<.05 \\ & \text { K } & 25.4 & 4.0 & & \\ \text { FREUD } & \text { F } & 6.8 & 1.7 & -4.11 & p<.001 \\ & \text { K } & 7.5 & 1.7 & & \end{array}$

Vomen were also more inclined toward a psychodynamic understanding of dreams than were men, though the difference between them was not great. This difference showed up on only two of the seven Psychodynamic scale 1tems (5 and 21). The greater difference was found on 1tem 21 ("People usually dream about what they are concerned with in their lives"), women averaging 4.3 compared with men's $3.9(t=4.36, p<.001)$.

Although neither men nor women were inclined toward a Freudian view of dreams, women rejected it more than did men. Although no significant differences were found in women's and men's embarrassment about their dreams (item 23), women disagreed more consistently with item four's assertion that "most dreams have to do with sex" ( $t=-4.27, p<.001)$. They were also more likely to disagree with item 36 , that "dreams are deliberately disguised" $(t=-3.45, p<.001)$.

Vomen also scored higher on non-scale 1 tems 28,31 , and 43 . Women were also more likely to disagree with item 33 ("In my religion, dreams are 
very important"). It is interesting to note that no significant sex differences were found on Factual scale items.

It is possible that the differences on the Attitude, Psychodynamic, and Freudian scales is due to gender differences in socialization. In our culture women are generally encouraged to attend more to their inner lives, whereas men are more often taught to override feelings that might interfere with their accomplishment of external goals. Paying more attention to their inner lives, women would be more likely to notice the relevance of their dreams, to understand them better, and to therefore appreciate them more. The differences in the Freudian scale might also be due to a real difference in the frequency of sexual themes in the dreams of men and women.

TABLE XI

SCHOOL DIFFEREICES IN SCALE SCORES

\begin{tabular}{llllll} 
Scale & School & Kean & S.D. & ERatio & Significance \\
\multirow{2}{*}{ ATTD } & H.S. & 33.7 & 5.0 & 3.34 & $p<.05$ \\
& C.C. & 32.5 & 4.6 & & \\
& Univ. & 34.0 & 4.6 & & \\
\multirow{2}{*}{ DYIII } & H.S. & 26.5 & 3.6 & 5.16 & $p<.01$ \\
& C.C. & 24.6 & 3.6 & & \\
& Univ. & 26.0 & 3.7 & & \\
\multirow{2}{*}{ PARA } & H.S. & 13.5 & 3.8 & 8.07 & $p<.001$ \\
& CC. & 11.8 & 3.2 & & \\
& Univ. & 11.9 & 3.5 & &
\end{tabular}

Differences were found in Attitude, Psychodynamic Orientation, and Paranormal Orientation from students at the three schools from which I drew my samples (see TABLE XI). An analysis of covariance controlling for 
age showed that none of these differences can be accounted for by the age differences among respondents from different schools.

When differences between schools are decomposed by testing pairs of schools individually we discover that the universtty sample has a more positive attitude about dreams than does the community college sample $(t=-2.47, p=.015)$. This is despite women's scoring higher on attitude and the communtty college sample's disproportionately large ratio of women to men. What might account for this difference? The community college from which the sample was drawn serves a more rural population than the unlversity. The high school, which like the university is located in an urban area, produced a score similar to the university's, though its difference from the community college was not statistically significant. Responses to the Psychodynamic scale exemplify the same pattern of differences, but to an even greater extent. While no differences were. evident between the high school and the universtty, the community college differed from both (C.C. / H.S., $t=3.37, p=.001$; C.C. $/$ Untv., $t=2.89$, $p=.005$ )

A different pattern emerges when we look at responses to the Paranormal Orientation scale. Here, no differences were found between the community college and the university, while both differed significantly from the high school (H.S. / CC., $t=3.17, p=.002$; H.S. / Untv., $t=3.70, p<$ $.001)$. One might assume that this difference is attributable to the age difference between the high school and the colleges. There is, however, no correlation between age and Paranormal Orientation $(r=-.01, \mathrm{n.s.})$, and the analysis of covariance was significant at the .001 level while controlling for age. The other difference between the samples is selectivity. About 
half of the high school students are not likely to enter college, and that half has already been excluded from the current college population. Further research might look both for differences between rural and urban populations and college educated and non-college educated adults.

\section{RELATIONSHIPS AMONG SCALES}

It was predicted that there would be a positive correlation between the Attitude and Factual Knowledge scales on the assumption that those who felt more positively about dreams would also be likely to know more about them. It turns out that the Attitude scale is positively correlated with all other scales except the Freudian scale, with which it has a slight negative correlation (see TABLE XII). The three items comprising the Freudian scale $(4,23,36)$ correlate negatively with the Attitude scale, though item 36 (disguise, -.15) accounts for the greatest share. All three also correlate negatively with the Factual scale, but here each contributes

TABLE XII

IITERSCALE CORRELATIOI MATRIX

$\begin{array}{llll}\text { ATTD } & \text { DYNM } & \text { FREUD } & \text { PARA }\end{array}$

DYHX $\quad .62$

FREUD $\quad-.12 * \quad .06 \mathrm{~ns}$

$\begin{array}{llll}\text { PARA } & .25 & .39 & .10 *\end{array}$

LUCID $\quad .23 \quad .23 \quad .01$ ns $.14 *$

$\begin{array}{llllll}\text { FACT } & .34 & .19 & -.33 & -.12 * & .07 \text { ns }\end{array}$

Unless otherwise indicated, p.<.001.

* $p<.01$.

* $p<.05$. 
substantially $(-.18,-.22$, and -.27 for items 4,23 , and 36 respectively). In contrast, item 37, which was designed to assess respondents' inclination toward a more Jungian perspective correlates positively with both the Factual scale $(.13, p>.01)$, and with the Attitude scale $(.21, p<.001)$.

Of special interest is the strong correlation between the Attitude and Psychodynamic scales. Examination of an interitem matrix for the two scales revealed that most items have a visibly higher average correlation with other items on their own scale than with the items on the other scale. There are two exceptions to this. First is 1 tem 7 ("Dreams can result in useful inventions"). Calculation shows item 7 to have a slightly higher average correlation (.27) with other items on the Attitude scale than with items on the Psychodynamic scale (.25). Psychodynamic scale 1tems that correlate most strongly with item 7 are 1tems 5 ("Dreams have hidden meanings"), and 22 ("Dreams are like a window into our subconscious"). Despite its close relationship with the Psychodynamic scale, item 7 belongs on the Attitude scale. Its inclusion on the Attitude scale is semantically coherent, whereas it is semantically distant from the concept of Psychodynamic Orientation.

The other 1tem is 1tem 41 ("Do you have any beliefs or theorles about dreams?"). Calculation shows it to have a stronger average correlation (.26) with the items on the Psychodynamic orientation scale than with the other items on the Attitude scale (.21). Item 41 correlates more strongly with 1tem 22 ("Dreams are like a window into our subconscious") from the Psychodynamic scale than with any other 1tem on the QAD. It would not be semantically coherent to include Item 41 on the Psychodynamic scale since it could logically refer to any sort of bellef or theory about dreams (e.g., 
"Dreams are generated by random neural discharges"). Item 41 does not make sense on the Psychodynamic scale. But should it be retained on the Attitude scale? Yes. It is positively correlated with all other items on the scale, it contributes to the internal consistency of the scale (.80 with, .79 without), and it loads on the same factor when the scale is analyzed separately.

It makes sense that the Attitude and Psychodynamic scales should be strongly intercorrelated. Those who believe that "dreams are like a window into our subconscious," and that "understanding dreams can make one's life better," are going to value them more. But these close interrelations are the second reason why the initial factor analysis on the whole extended QAD produced an uninterpretable pattern of factors.

\section{CONTEHT VALIDITY}

Item III ("Do you have any beliefs or theories about dreams, and if yes, what are they?") was included partially as an indicator of attitude, but its primary purpose was to see whether respondents had any bellefs about dreams that were not reflected in existing QAD items. A majority of my respondents (62\%) answered item III affirmatively, and all but two wrote something about their bellefs. The overwhelming majority of responses were clearly covered by existing QAD 1tems. The most frequently occuring Ideas were (1) that dreams sometimes predict the future, (2) that they are an expression of the subconscious mind, and (3) that they reflect our waking concerns. Hany other responses were varlations on numbers (2) and (3) above. For example, several respondents suggested that dreams reflect our "true" thoughts, feelings, and desires. Emotion, not specifically mentioned 
in any QAD items, was mentioned by a few respondents. Several wrote that dreams express our worries and fears, though nightmares were spectfled only three times. Five respondents suggested that dreams are a way of releasing anxiety, stress, or tension, and a sixth wrote that they "help me keep my sanity" during stressful times. Five of these agreed with 1tem 37 ("The purpose of dreams is to restore balance to the mind"), while one was not sure.

A few described dreams as uninhtbited or unrestrained thoughts. Nine described dreams as resulting from the subconsclous attempting to communtcate with the conscious mind, "trying tell you something." Several mentioned dreams as a form of problem solving, and one spectfically mentioned that in dreams her subconscious is telling her something she has been denying. Freud and Jung were explicitly mentioned twice, but nothing spectfic was said about elther of them.

Several respondents belleved that dreams are "sometimes" meaningful, but sometimes not. Two wrote that dreams involve random processes, and another described than as being a "conglomeration" of thoughts, feelings, and memorles. One subject even suggested that some dreams are "mere entertainment for the mind because the body is sleeping and it gets bored."

One of my subjects referred to dreams as occuring during REM states. Two subjects (including the one quoted below) suggested that dreams are a way of clearing space for new information. Some respondents described some elaborate and complex beliefs:

In rare, very rare instances, they can be "revelation" from a Supreme Being ..... Scientifically speaking, dreams may be Just the normal functioning of the brain at the end of the day to get rid of accumulated sense data which have built up, sort 
of like a "master clear" on a computer. But the way the sense data is configured may have some psychological reasoning behind it.

A few other topics not explicitly included in the QAD were mentioned. Repeating dreams were mentioned by one respondent, but the reference was vague. One respondent belleved that dreams "always [go] back to religious principles," and one suggested that dreams reflect "spiritual activity involving the influences of external spiritual beings interacting with the mind." Another thought that dreams "can be messages or plctures of past Iffe" Overall, the extended QAD demonstrated good content validity, as it included most topics mentioned in subjects' open-ended responses. 


\section{COHCLUSION}

The creation of scales proved useful in two ways. First, it enabled us to demonstrate the rellabllity of a subset of QAD items for assessing respondents' attitudes, psychodynamic orientation, and to a lesser degree paranormal orientation. We have not demonstrated a reliable measure of factual knowledge about dreams. Second, the scales brought a good deal of order and coherence to subjects' responses. Overall, respondents possess a positive attitude or valence toward dreams, and are generally inclined toward a psychodynamic understanding of thetr nature. The qualification to this is that some specifically psychoanalytic views are eschewed by most students. Most respondents were not inclined toward a paranormal or supernatural view of dreams, though they were divided over whether God can communicate to us through dreams. Lucid dreaming turned out to be a common occurrence, $72 \%$ of respondents reporting at least occasional lucidity. Respondents' factual knowledge appears to be rather unstructured.

Positive attitudes toward dreams were strongly related with psychodynamic orientation, and moderately related with factual knowledge and lucidity. Positive attitudes were negatively related to speciftcally psychoanalytic notions of dreaming. Few age differences were found, and those found were weak. Significant sex differences were found, with women holding substantially stronger positive attitudes toward dreams than did men. Women were also moderately more inclined toward a psychodynamic understanding of dreams than were men. On the other hand, women were 
substantially more averse than were men to a speciflcally psychoanalytic conception of dreams. Substantial differences were also found between schools in attitude, psychodynamic orientation, and paranormal orientation, though more research w1ll be required if the causes of these difference are to be understood with any certainty.

\section{FUTURE RESEARCH}

This study provides groundwork for future research with a larger general population. Several questions immediately suggest themselves. Will age differences emerge with a broader population and a less restricted age range? Are geographical influences associated with orientations toward dreams? Is socioeconomic status a relevant factor?

Before proceeding with another population, however, I would suggest a few changes and additions to the Extended Questionnaire About Dreams. First, I suggest rewording items 24,28 , and 31 . Item 24 should be reworded to be less ambiguous: "We usually dream while we are most soundly asleep." Item 28 should be modified to reflect some clearly demonstrated influence on dream recall: "People who pay a lot of attention to their inner lives remember their dreams better than those who don 't." And Item 31 should be replaced with a more readily demonstrable proposition: "Different people have different styles of dreaming." Other items should be added to reflect topics generated in response to item III. These items should deal with truth in dreams, random processes in dreaming, dreams as clearing the brain of useless information, dreams as a source of stress or tension release, and the nature of nightmares and repetative dreams. It would 
also be valuable to add an item about the untversality of dream symbolism. Finally, since some degree of lucidity appears to be a common phenomenon, it would be useful to add an item to assess more specifically how aware subjects are in their dreams. 


\section{REFEREICES}

Antrobus, J. S., Dement, W. \& Fisher, C. (1964), Patterns of dreaming and dream recall: an EEG study. Journal of Abnormal and Soctal Psychology, 69, 341-344.

Aristotle (1952). On dreams (J. I. Beare, Trans.). In Hutchings, R. M. (Ed.) Great Books of the Vestern Vorld, 8, pp. 702-706. Chicago: Encyclopedia Britannica.

Aserinsky, E., \& Kleitman, I., (1953). Regularly occuring periods of eye motility and concomitant phenomena during sleep. Science, 118, 273-274.

Begley, S. (1989, August 14). The stuff that dreams are made of. Newsweek, pp. 41-44.

Books in print. (1989). Subject guide (Vol. 2, pp. 1989-1991). New York: R. R. Bowker.

Campbell, D. T., \& Fiske, D. W. (1959). Convergent and discriminant validation by the multitrait-multimethod matrix. Psychological Bulletin, 56, 81-105.

Cartwright, R. D. (1978). A primer on sleep and dreaming. Menlo Park, CA: Addison-Wesley.

Cernovsky, 2. Z. (1984). Dream recall and att1tude toward dreams. Perceptual and Motor Ski1ls, 58, 911-914.

Cernovsky, 2. 2. (1987). Attitude towards dreams and MMPI measures of psychopathology in male chronic alcoholics. Psychology, 24, 30-32.

Colligan, R. C., Osborne, D., Swenson, W. M., \& Offord, K. P. (1983). The MMPI: A contemporary normative study. New York: Praeger.

Crick, F., \& Mitchison, G. (1983). The function of dream sleep. Hature, 304, 111-114.

Cronbach, L. J. (1951). Coefficient alpha and the internal structure of tests. Psychometrika, 16, 297-334.

Dement, W. C. (1976). Some must watch while some must sleep. New York: Norton.

Do your dreams have any meaning? (1989, July). USA Ioday, p. 10. 
Domino, G. (1982). Attitudes toward dreams, sex differences, and creativity. Journal of Creative Behavior, 16, 112-122.

Faraday, A. (1972) Dream Power. New York: Berkley Books.

Freud, S. (1953). The interpretation of dreams. In J. Strachey (Ed. and Trans.), The standard edition of the complete psychological works of Sigmund Freud (Vols. 4 \& 5, pp. 1-627). London: Hogarth Press. (Original work published 1900)

Gackenbach, J. \& Bosveld, J. (1989, August). Take control of your dreams. Esychology Today, pp, 27-32.

Gelman, D. (1989, August 14). Dreams on the couch. Newsweek, pp. 45-47.

Hall, C. S. (1966). The meaning of dreams. New York: McGraw-Hill, COriginal work published 1953)

Hall, C. S., \& Van de Castle, R. (1966). The content analysis of dreams. Hew York: Appleton-Century-Crofts.

Hobson, J. A. (1988). The dreaming brain. New York: Basic Books.

Jung, C. G. (1964). Approaching the unconscious. In C. G. Jung (Ed.) Lan and his symbols (pp. 1-94). Hew York: Dell.

Jung, C. G. (1969). General aspects of dream psychology. (R. F. C. Hull, Trans.) In H. Read, M. Fordham, G. Adler, \& W. McGuire (Eds.) The collected works of C. G. Jung (2nd ed.) (Vol. 8, pp. 237-280). New Jersey: Princeton University Press. (Original work published 1916)

Jung, C. G. (1969). Psychology and religion. (R. F. C. Hull, Trans.) In H. Read, M. Fordham, G. Adler, \& W. McGuire (Eds.) The collected works of C. G. Jung (2nd ed.) (Vol. 11, pp. 3-105). New Jersey: Princeton University Press. (Original work published 1938)

LaBerge, S. P. (1980). Lucid dreaming: An exploratory study of consclousness during sleep. Dissertation Abstracts International, 41, 1966. (University Microfilms No. 80-24, 691)

LaBerge, S. P. (1985). Lucid dreaming: The power of being awake and aware in your dreams. New York: Ballantine.

LaBerge, S. P., \& Dement, W. C. (1982), Laterallzation of alpha activity for dreamed singing and counting during REY sleep. Psychophysiology, 19, $331-332$.

LaBerge, S. P., Greenleaf, W., \& Kedzlersk1, B. (1983). Physlological responses to dreamed sexual activity during lucid REM sleep. Esychophysiology, 20, 454-455. 
Loevinger, J., Gleser, G. C., \& DuBois, P. H. (1953). Maximizing the discriminating power of a multiple-score test. Psychometrika, 18, 309-317.

Maury, A. (1878). Le Sommel] et les reves [Sleep and dreams]. Paris: Didier \& Cie, (Original work published 1861)

Robbins, P. R. \& Tanck, R. H. (1988). Interest in dreams and dream recall. Berceptual and Yotor Skills, 66, 291-294.

Saint-Denys, H. (1982). Dreams and how to gutde them. London: Duckworth. (Original work published 1867)

Schatzman, K. (1989). Are dreams really meaningful? Association for the Study of Dreams Newsletter, 6, 1-2. (Avallable from the Association for the Study of Dreams, c/o Counseling \& Career Planning, California State University, Chico, CA 95929-0702)

Starker, S. (1982), Eantastic thought: A11 about dreams, daydreams, hallucinations, and hypnosis. Englewood Cliffs, IJ: Prentice-Hall.

Wood, J. M., Sebba, D., \& Domino, G. (1989-90). Do creative people bave more bizarre dreams? A reconsideration. Imagination. Cognition and Personality, 2, 3-16. 


\section{APPENDIX A}

ORIGINAL QUESTIONNAIRE ABOUT DREAMS (QAD) ITEMS 
ORIGIMAL QUEST IONNAIRE ABOUT DREAMS ITEMS (DOMInO, 1982)

1. Everyone dreams every night.

2. Dreams are basically sllly and not important.

3. Dreams often predict the future.

4. Most dreams have to do with sex.

5. Dreams have bidden meanings.

6. Dreams are a way by which the dead speak to us.

7. Dreams can result in useful inventions.

8. Some people never dream.

9. Dreams occur in black and whtte (rather than in color).

10. Dreams can be used to create a poem, a painting, or a work of art.

11. Bizarre dreams are a sign of mental illness.

12. God can speak to us through dreams.

13. What we dream about is usually what happened the day before.

14. OId people often dream about dying.

15. Dreams reflect goals we wish to achieve.

16. Understanding one's dreams can make your life better.

17. I make a special effort to remember my dreams.

18. During dreams the soul is released from the body and wanders around.

19. Most dreams occur because of what we eat (as for example, indigestion).

20. I would like to understand my dreams better.

21. People usually dream about what they are concerned with in their lives.

22. Dreams are like a window into our subconscious.

23. The dreams I remember are usually embarrassing.

24. The more soundly we are asleep, the more likely we are to dream. 
25. Dreams are full of symbols.

26. It is possible to declde before falling asleep, what one will dream about.

27. Most dreams involve activities and settings that are very unusual and fantastic.

28. Remembering one's dreams is a sign of a good lmagination.

29. People born blind do not dream.

30. Only humans dream; dogs and other animals do not dream.

31. Dreams are like your personality; if you're a happy person your dreams will be happy.

32. Usually, dreams reflect what is gaing on around you while you sleep; for example, a dripping faucet will cause you to dream about water.

33. In my religion, dreams are very important.

34. The analysis of dreams is a silly thing. 


\section{APPENDIX B}

ATTITUDES TOWARD DREAMS SCALE (ATDS) ITEMS 
ATTITUDES TOWARD DREAMS SCALE (ATDS) ITEMS (Cernovsky, 1984)

1. Most people have no interest in dreams.

2. Those who discuss their dreams with others are probably not well adjusted.

3. The members of my family used to talk about the dreams they had.

4. Most of the people around me do not care for dreams.

5. I believe that dreams are one of the most important ways to understand myself.

6. I do not pay any attention to my own dreams.

7. Most of the people who are important to me do not pay any attention to their dreams.

8. Dreams have no meaning.

9. Dreams are too confused to have any meaning to me.

10. I do not believe that dreams influence the life of people in any major way.

11. I dislike speculation about the meaning of dreams.

12. Kost of my friends would like to know more about dreams.

13. When someone speaks about a dream, I expect the listeners to laugh, or to criticize this person either directly or behind his back.

14. When someone talks about his or her dreams, I expect the listeners to view this person as unrealistic, unpractical, and possibly as weak.

15. Most of my best friends view dreams as very interesting and meaningful.

16. Those who try to discuss their dreams in public will only regret it later.

17. Practical everyday life is too important to me to pay any attention to my dreams. 
APPENDIX C

EXTENDED QUEST IONNAIRE ABOUT DREAMS 
$\begin{array}{cccc}\begin{array}{c}\text { Strongly } \\ \text { Agree }\end{array} & \text { Ifot } & \text { Dis- } & \text { Strongly } \\ \text { Disagree }\end{array}$

4. Most dreams have to do with sex.

5. Dreams have hidden meanings.

1

6. Dreams are a way by which the dead 2

3

4

5 speak to us.

7. Dreams can result in useful inventions.

1

8. Some people never dream.

1

9. Dreams occur in black and white

(rather than in color).

10. Dreams can be used to create a poem,

1

2

3

4

5

1

2

3

5

a painting, or a work of art.

11. Bizarre dreams are a sign of mental illness.

$\begin{array}{lllll}1 & 2 & 3 & 4 & 5\end{array}$

12. God can speak to us through dreams.

13. What we dream about is usually what happened the day before.

14. Old people often dream about dying.

15. Dreams reflect goals we wish to achleve.

$\begin{array}{lllll}1 & 2 & 3 & 4 & 5 \\ 1 & 2 & 3 & 4 & 5\end{array}$

16. Understanding one's dreams can nake your life better.

$\begin{array}{lllll}2 & 2 & 3 & 4 & 5\end{array}$

17. I make a special effort to renember

1

1

1

2

3

4

my dreams.

18. During dreams the soul is released from the body and wanders around.

1

1

19. Kost dreams occur because of what we eat (as for example, indigestion).

20. I would like to understand my dreams better.

$\begin{array}{lllll}1 & 2 & 3 & 4 & 5\end{array}$

21. People usually drean about what they are concerned with in their lives.

$\begin{array}{llll}2 & 3 & 4 & 5\end{array}$

22. Dreams are like a window Into our subconsctous.

$\begin{array}{llll}2 & 3 & 4 & 5\end{array}$




$\begin{array}{ccccc}\text { Strongly } & & \text { Iot } & \text { Dis- } & \text { Strongly } \\ \text { Agree } & \text { Agree } & \text { Sure } & \text { agree } & \text { Disagree }\end{array}$

23. The dreams I remember are usually

1

2

3

4

5

embarrassing.

24. The more soundly we are asleep, the

1

2

3

4

5

more likely we are to dream.

25. Dreams are full of symbols.

1

2

$3 \quad 4 \quad 5$

26. It is possible to dectde before

1

falling asleep, what one will dreaw about.

27. Most dreams 1nvolve activitles and and settlings that are very unusual and fantastic.

28. Remembering one's dreams is a sign of a good imagination.

1

\begin{tabular}{|c|}
\hline 2 \\
\hline
\end{tabular}

29. People born blind do not dream.

1

30. Only humans dream; dogs and other animals do not dream.

31. Dreams are like your personality; if

1 you're a happy person your dreams w1ll be happy.

32. Dreams can reflect what is going

33. In my religion, dreams are very 1mportant.

34. The analysis of dreams is a silly th1ng.

$\begin{array}{lllll}1 & 2 & 3 & 4 & 5\end{array}$

$\begin{array}{lllll}1 & 2 & 3 & 4 & 5\end{array}$

35. Even dreams that seem to last nearly an hour happen in only an instant.

36. Dreams are dellberately disguised to hide their true meanings from us.

$\begin{array}{lllll}1 & 2 & 3 & 4 & 5\end{array}$

37. The purpose of dreams is to restore balance to the mind.

1

1

2

3

5

38. In my dreams I sometimes know that I am dreaming.

1

$\begin{array}{llll}2 & 3 & 4 & 5\end{array}$

1

$\begin{array}{llll}2 & 3 & 4 & 5\end{array}$

$\begin{array}{lllll}2 & 3 & 4 & 5\end{array}$

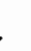

2

3

4 


\section{APPENDIX D}

PROVISIONAL QAD SCALES 
PROVISIONAL QAD SCALES

\section{Provisional Attitude Scale}

2. Dreams are basically silly and not important.

17. I make a spectal effort to remember my dreams.

20. I would like to understand my dreams better.

23. The dreams I remember are usually embarrassing.

33. In my religion, dreams are very important.

34. The analysis of dreams is a silly thing.

38. In my dreams I sometimes know that I am dreaming.

I. Have you ever speculated about the possible meaning of one of your dreams?

II. Have you ever discussed one of your dreams with someone else?

III. Do you have any beliefs or theorles about dreams?

IV (a). Have you ever read a book or magazine article about dreams?

IV (b). If yes, how many?

\section{Provisional Psychodynamic Orientation Scale}

4. Most dreams have to do with sex.

5. Dreams have hidden meanings.

16. Understanding one's dreams can make your life better.

22. Dreams are like a window into our subconscious.

25. Dreams are full of symbols.

36. Dreams are deliberately disguised to hide their true meanings from us.

37. The purpose of dreams is to restore balance to the mind. 


\section{Provisional Paranormal Orientation Scale}

3. Dreams often predict the future.

6. Dreams are a way by which the dead speak to us.

12. God can speak to us through dreams.

18. During dreams the soul is released from the body and wanders around.

\section{Provistonal Factual Knowledge Scale}

1. Everyone dreams every night. (T)

7. Dreams can result in useful inventions. ( $T$ )

8. Some people never dream. (F)

9. Dreams occur in black and white (rather than in color). (F)

10. Dreams can be used to create a poem, a painting, or a work of art. (T)

11. Bizarre dreams are a sign of mental illness. (F)

13. What we dream about is usually what happened the day before. (F)

14. Old people of ten dream about dying. (F)

15. Dreams reflect goals we wish to achleve. ( $T$ )

19. Most dreams occur because of what we eat (as for example, indigestion). (F)

21. People usually dream about what they are concerned with in thetr lives. ( $T$ )

24. The more soundly we are asleep, the more likely we are to dream. (F)

26. It is possible to decide before falling asleep, what one will dream about. (T)

27. Most dreams involve activities and settings that are very unusual and fantastic. (F) 
29. People born blind do not dream. (F)

30. Only humans dream; dogs and other animals do not dream. (F)

32. Dreams can reflect what is going on around you while you sleep; for example, a dripping faucet might cause you to dream about water. (T)

35. Even dreams that seem to last nearly an hour happen in only an instant. (F) 


\section{APPENDIX E}

FINAL QAD SCALES 


\section{FINAI QAD SCALES}

Attitude Scale (alpha $=.80$ )

2. Dreams are basically silly and not important. (.68)

7. Dreams can result in useful inventions. (.55)

10. Dreams can be used to create a poem, a painting, or a work of art. (.47)

17. I make a special effort to remember my dreams. (.63)

20. I would like to understand my dreams better. (.70)

34. The analysis of dreams is a silly thing. (.67)

I. Have you ever speculated about the possible meaning of one of your dreams? (.75)

II. Have you ever discussed one of your dreams with someone else? (.56)

III. Do you have any bellefs or theorles about dreams? (.46)

IV(a). Have you ever read a book or magazine article about dreams? (.41)

Psychodynamic Orientation Scale (alpha $=.76$ )

5. Dreams have hidden meanings. (.64)

15. Dreams reflect goals we wish to achleve, (.59)

16. Understanding one's dreams can make your life better. (.56)

21. People usually dream about what they are concerned with in their 11ves. (.67)

22. Dreams are like a window into our subconscious. (.58)

25. Dreams are full of symbols. (.65)

37. The purpose of dreams is to restore balance to the mind. (.24) 
Ereudian Orientation Scale (alpha $=.41$ )

4. Most dreams have to do with sex. (.57)

23. The dreams I remember are usually embarrassing. (.55)

36. Dreams are deliberately disguised to hide their true meanings from us. (.26)

Eactual Knowledge Scale (alpha $=.46$ )

1. Everyone dreams every night. (.76, factor 2)

8. Some people never dream. (.85, factor 2)

9. Dreams occur in black and white (rather than in color). (.67, factor 4)

11. Bizarre dreams are a sign of mental 1llness. (.45, factor 4)

13. What we dream about is usually what happened the day before. $(.78$, factor 3$)$

14. Old people often dream about dying. (.68, factor 3)

19. Most dreams occur because of what we eat (as for example, Indigestion). (.45, factor 4)

27. Most dreams involve activities and settings that are very unusual and fantastic. (.85, factor 5)

29. People born blind do not dream. (.72, factor 1)

30. Only humans dream; dogs and other animals do not dream. (.79, factor 1)

32. Dreams can reflect what is going on around you while you sleep;

for example, a dripping faucet might cause you to dream about water. (.58, factor 4)

35. Even dreams that seem to last nearly an hour happen in only an instant. $(.58$, factor 5) 
Paranormal Orientaion Scale (alpha $=.66$ )

3. Dreams of ten predict the future. (.69)

6. Dreams are a way by which the dead speak to us. (.77)

12. God can speak to us through dreams. (.49)

18. During dreams the soul is released from the body and wanders around. (.73)

33. In my religion, dreams are very important. (.58)

Lucidity Scale (alpha $=.41$ )

26. It is possible to decide before falling asleep, what one will dream about. (.62)

38. In my dreams I sometimes know that I am dreaming. (.62)

Miscellaneous Items (not included on any scale)

24. The more soundly we are asleep, the more likely we are to dream.

28. Remembering one's dreams is a sign of a good imagination.

31. Dreams are like your personality; if you're a happy person your dreams w1ll be happy.

IV (b). If yes (on \#42), how many? 
Eactual Knowledge Subscales

Who Dreams (alpha $=.58$ )

1. Everyone dreams every night. (.72)

8. Some people never dream. (.62)

29. People born blind do not dream. (.69)

30. Only humans dream; dogs and other animals do not dream. (.62)

External Influences (alpha $=.39$ )

13. What we dream about is usually what happened the day before. (.79)

14. Old people often dream about dying. (.69)

19. Most dreams occur because of what we eat (as for example, indigestion). (.47)

Continuity with Vaking Cognition (alpha $=.28$ )

9. Dreams occur in black and white (rather than in color). (.58)

27. Most dreams involve activities and settings that are very unusual and fantastic. (.56)

35. Even dreams that seem to last nearly an hour happen in only an instant. (.68) 